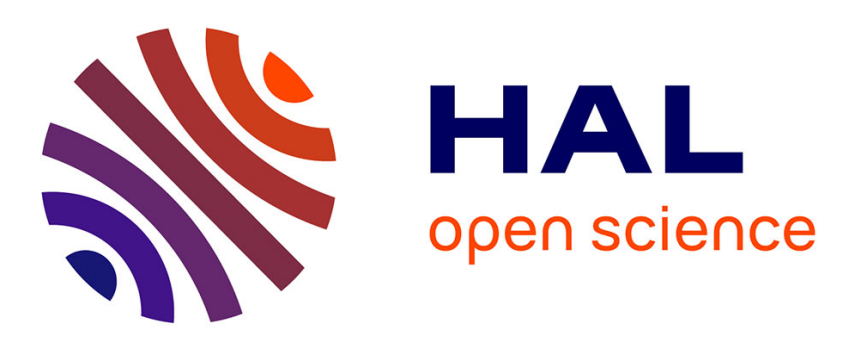

\title{
SUBPICOSECOND SPECTROSCOPIC STUDIES OF SINGLET EXCITON FUSION IN MOLECULAR SOLIDS
}

\author{
B. Greene, R. Millard
}

\section{- To cite this version:}

B. Greene, R. Millard. SUBPICOSECOND SPECTROSCOPIC STUDIES OF SINGLET EXCITON FUSION IN MOLECULAR SOLIDS. Journal de Physique Colloques, 1985, 46 (C7), pp.C7-371-C7376. 10.1051/jphyscol:1985766 . jpa-00225095

\section{HAL Id: jpa-00225095 https://hal.science/jpa-00225095}

Submitted on 1 Jan 1985

HAL is a multi-disciplinary open access archive for the deposit and dissemination of scientific research documents, whether they are published or not. The documents may come from teaching and research institutions in France or abroad, or from public or private research centers.
L'archive ouverte pluridisciplinaire HAL, est destinée au dépôt et à la diffusion de documents scientifiques de niveau recherche, publiés ou non, émanant des établissements d'enseignement et de recherche français ou étrangers, des laboratoires publics ou privés. 
JOURNAL DE PHYSIQUE

Colloque C7, supplément au $n^{\circ} 10$, Tome 46 , octobre 1985

page $C 7-371$

SUBPICOSECOND SPECTROSCOPIC STUDIES OF SINGLET EXCITON FUSION IN

MOLECULAR SOLIDS

\author{
B.I. Greene and R.R. Millard \\ ATQT Bell Laboratories, Murray Hill, New Jersey 07974, U.S.A.
}

\begin{abstract}
The first kinetic data displaying a time-dependent $\left(t^{-1 / 2}\right)$ singlet exciton annihilation rate has been observed. Subpicosecond optical excitation of polycrystalline thin-film samples of $\beta$-hydrogen phthalocyanine resulted in excitonic saturation of the crystal lattice. The initial exciton decay yields the only unambiguous measurement of a characteristic annihilation interaction rate for molecular excitons on adjacent lattice sites. Spectroscopic evidence suggests that fusion events produce vibrationally athermal ground state molecules.
\end{abstract}

Energy transfer together with exciton motion and decay in molecular solids has been persistently studied over the past twenty years. ${ }^{(1-8)}$ Several microscopic theories and pictures have been presented to explain frequency as well as time domain measurements and observations. To date however, no time resolved measurements on any molecular crystal system have shown any evidence of the the microscopically detailed and discrete nature of these dynamical processes. In this paper we present and discuss the first such data.

Previous time-resolved studies on singlet exciton annihilation have monitored wavelength integrated fluorescence intensity following pulsed optical excitation to probe excited-state population densities. In the present study, we employ the technique of sub-picosecond timeresolved absorption spectroscopy which has the advantages of combining laser pulsewidth-limited temporal resolution with valuable spectroscopic information obtainable as broad-banded optical absorption spectra.

Samples consisted of polycrystalline thin-films of $\beta$-hydrogen phthalocyanine $\left(\mathrm{H}_{2} \mathrm{Pc}\right)$. While not the classic subject of investigation that for instance anthracene has been, $\mathrm{H}_{2} \mathrm{Pc}$ has several important properties critical to the success of the present measurements. The material is highly absorbing at our laser fundamental $\left(16,000 \mathrm{~cm}^{-1}\right)$ with $\alpha \approx 2 \times 10^{5} \mathrm{~cm}^{-1}$. High excitation densities (ca. $10^{21} \mathrm{~cm}^{-3}$ ) are therefore obtainable with available excitation energies and intensities. $\mathrm{H}_{2} \mathrm{Pc}$ is readily sublimed to form good optical quality amorphous films, which can be subsequently annealed to yield polycrystalline samples. These films have been well characterized. ${ }^{(9-12)}$ Spectroscopic and crystallographic evidence supports the notion that the individual microcrystallites (which have a flake-like morphology and in-plane dimensions of 10$100 \mu$ ) are isomorphous with the $\beta$-form of the macroscopic single crystal. The films showed a remarkable resistance to optical damage at all reported excitation intensities. Finally, $\mathrm{H}_{2} \mathrm{Pc}$ exhibits an intense excited state absorption spectrum, with transitions in the visible at least five times stronger than those observed in anthracene. 
Measurements were performed utilizing amplified laser pulses obtained from a colliding pulse ring dye laser. ${ }^{(13)}$ These pulses were $0.15 \mathrm{ps}$ FWHM, centered at $625 \mathrm{~nm}\left(16,000 \mathrm{~cm}^{-1}\right)$ and occurred at a repetition rate of $10 \mathrm{~Hz}$. Pump and probe measurements were performed utilizing pulses at the fundamental wavelength and white light continuum pulses respectively. Details of the experimental technique have been presented previously. ${ }^{(14)}$

Figure 1 displays the ground state absorbance spectrum of a typical $\mathrm{H}_{2} \mathrm{Pc}$ sample together with transient absorbance difference spectra taken at three different delay times. The sample was held at $4 \mathrm{~K}$. The difference spectra reveal regions of bleaching (due to ground state depopulation) in addition to regions of excited state absorption.
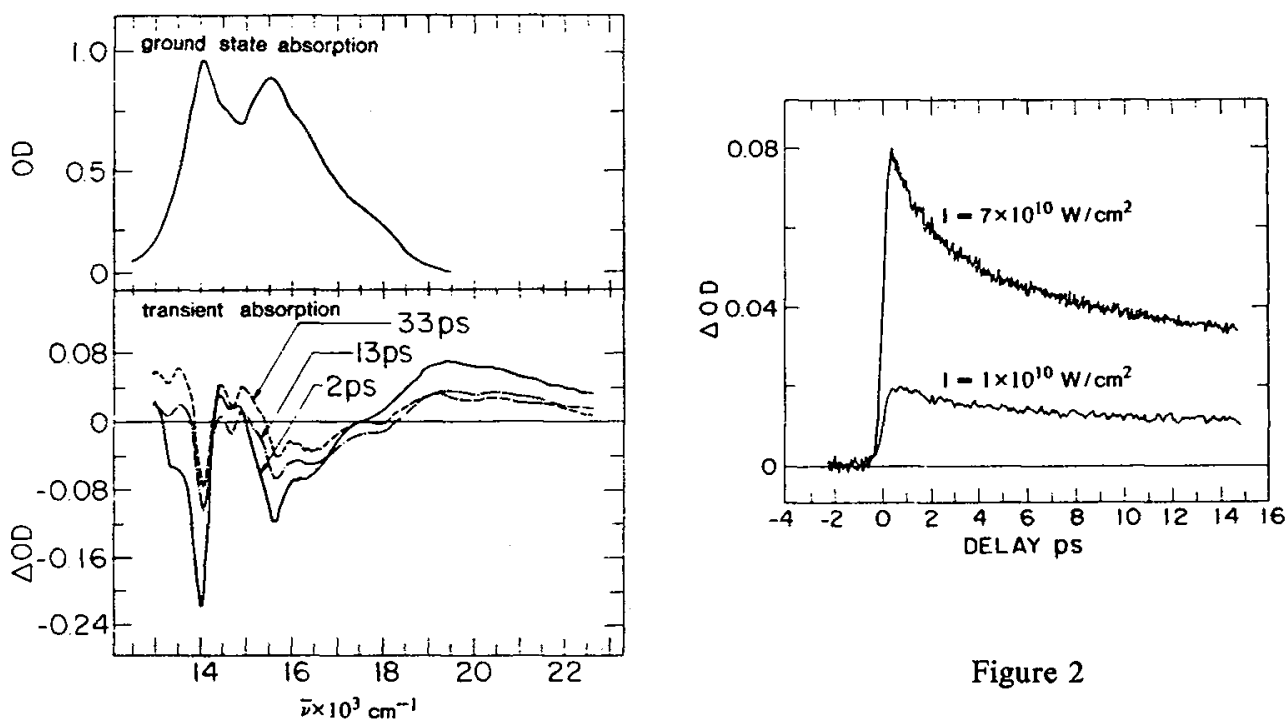

Figure 1

As the delay time was increased, a dramatic evolution of the entire difference spectrum was observed. Over the first $10 \mathrm{ps}$ subsequent to excitation, there was a rapid decay of the initially induced transient spectrum. This is due to a nonradiative process which efficiently depopulates the initially prepared exciton population. We choose to probe kinetics at a spectral position where the observed signal can be unambiguously related to the exciton number density. Such a spectral region occurs in the area of excited state absorption between $19,000 \mathrm{~cm}^{-1}$ and $22,000 \mathrm{~cm}^{-1}$, where due to a minimal ground state absorption, there can be little contribution from ground state recovery processes manifest in the signal. We observe the spectral shape of the excited state absorption in this region to remain constant throughout the decay. In contrast, the spectral evolution occuring at energies below $16,000 \mathrm{~cm}^{-1}$ is quite complex. In particular, a dramatic increase in sample absorption occurs at roughly $13,500 \mathrm{~cm}^{-1}$, where an initial net bleaching rapidly evolves into a persistent net increase in sample absorbance lasting longer than 200 ps.

Figure 2 displays single wavelength pump and probe data obtained with pump pulses at $16,000 \mathrm{~cm}^{-1}$ and probe pulses at $19,500 \mathrm{~cm}^{-1}$ for two different pump intensities. The decay of these signals was observed to be highly non-exponential. These kinetic traces were observed to be independent of sample temperature over the range $4 \mathrm{~K}$ to $300 \mathrm{~K}$. 
We note that the initial rapid decay of the induced absorbance signal is due to singlet exciton-exciton annihilation. This non-radiative phenomenon has been observed in many kinetic studies of molecular crystals where high densities of excitons are created. This certainly corresponds to our experimental conditions, where with the highest intensity excitation pulses $\left(55 \mu \mathrm{J} /\right.$ pulse, $\left.7 \times 10^{10} \mathrm{~W} / \mathrm{cm}^{2}\right)$, we estimate exciton densities of approximately $1.0 \pm 0.5 \times 10^{21} \mathrm{~cm}^{-3}$. Single crystal specific gravity measurements indicates a value for total saturation to be $1.68 \times 10^{21} \mathrm{~cm}^{-3}$. (15)

A simple phenomenological rate equation describing exciton decay is often written:

$$
\frac{\mathrm{dN}}{\mathrm{dt}}=-\mathrm{kN}-\gamma \mathrm{N}^{2}
$$

where $\mathbf{k}$ is the time-independent "unimolecular" decay rate describing a reciprocal exciton lifetime in the low density limit, and $\gamma$ is the time-independent "bimolecular" annihilation rate constant. For the present discussion we disregard the unimolecular term in Eq. (1). At the exciton densities at which our experiments were performed this term describes a rate process much slower than the bimolecular term.

In principle, time-dependent energy transfer rates are expected in measurements of exciton trapping and annihilation. This arises from the fact that subsequent to the initial creation of a spacially homogeneous exciton population, proximate pairs of excitons, or excitons closest to traps, will interact first. Progressively greater and greater remaining mean interparticular distances result in decreasing characteristic interaction rates. Both motion-limited diffusion theory, and the Förster long range dipole-dipole interaction picture (in the absence of diffusion) lead to a $t^{-1 / 2}$ dependence for either $k$ or $\gamma \cdot{ }^{(4,16)}$

For annihilation dominated kinetics, equation 1 is written to explicitly include the time dependence of the rate:

$$
\frac{\mathrm{dN}}{\mathrm{dt}}=-\gamma \mathrm{t}^{-\frac{1}{2}} \mathrm{~N}^{2}
$$

Integration of equation (2) yields an expression for the exciton number density as a function of time:

$$
N(t)=\left(2 \gamma t^{\frac{1}{2}}+\frac{1}{N_{0}}\right)^{-1} .
$$

Figure 3 displays time resolved absorption data (such as appears in Figure 2) plotted in the form $\left(\frac{1}{N}-\frac{1}{N_{0}}\right)$ vs. $\sqrt{t}$. Kinetics obeying the rate law (Eq. (2)) will yield a straight line with slope $2 \gamma$. This is observed to be the case, yielding $\gamma=1.0 \pm 0.5 \times 10^{-16} \mathrm{~cm}^{3} \mathrm{~s}^{-1 / 2}$, corrected for the fact that in a sub-saturation regime, a non-uniform excitation density exists from the front to the back of the sample.

It is important to note that the line drawn through the data points in Fig. 3 does not go through the origin. This is not due to an uncertainty in the origin of time (on the order of a pulsewidth), as such displacements make only a minor change in the appearance of the curve. Rather, we attribute this effect to the discrete nature of the crystal lattice being inadequately described by a model assuming a continuous distribution of exciton-exciton spacings. As the delay times decrease, the annihilation rate should increase, corresponding to shorter and shorter mean exciton-exciton separations. Clearly though, a maximum rate exists, which corresponds to the 
interaction of excitons on adjacent lattice sites. The extropolation of the straight line though the data in Figure 3 is therefore expected to indicate excessive values of $\mathbf{N}_{0}$ at the origin of time.

Excitonic saturation of the $\mathrm{H}_{2} \mathrm{Pc}$ lattice facilitates a clear and simple interpretation of the initial rapid signal decay. Since the majority of excitons will have excitons as nearest neighbors, we propose that a single exponential fit to the data at the earliest delay times corresponds to the lifetime of proximate excitons. Over the first picosecond, such a fit is quite good yielding a temperature-independent lifetime of 5.7 ps (Fig. 4). This observed lifetime was independent of pump intensity for intensities above ca. $3 \times 10^{10} \mathrm{~W} / \mathrm{cm}^{2}$. We expect that as the sample becomes saturated, the early time decay rate will be dominated by the single exponential rate associated with proximate exciton pairs. As such, this study presents the only measurement of an exciton annihilation rate free from the ambiguity or possible influence of exciton motion.

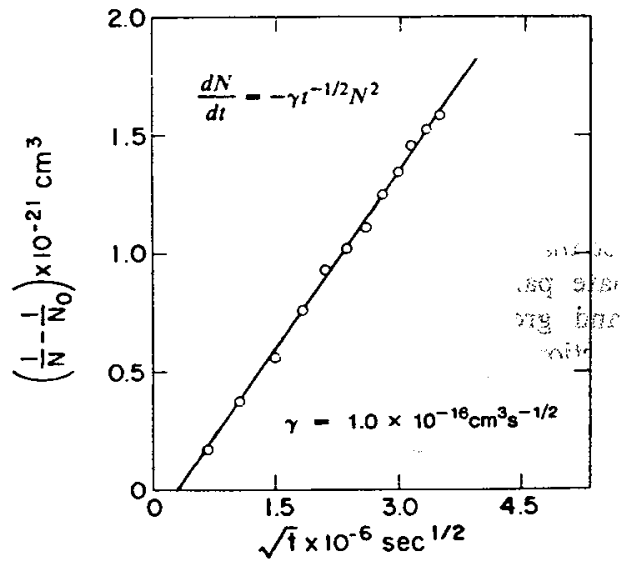

Figure 3

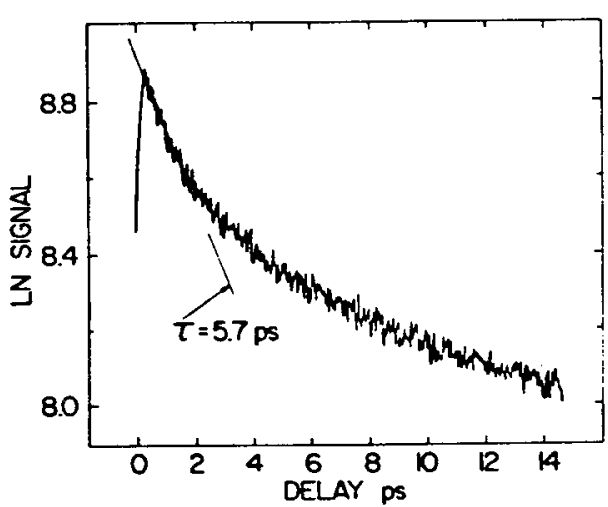

Figure 4

Data shown in Figure 2 is the first to manifest a clear and unmistakable time-dependent annihilation rate. The rate law (Eq. 2) is followed down to delay times of roughly $0.7 \mathrm{ps.} \mathrm{We}$ suggest that at least for the case of $\mathrm{H}_{2} \mathrm{Pc}$, the rate associated with pure annihilistic interactions is quite small compared with approximations sometimes made for exciton hopping rates. As Kenkre and Schmid suggest, the "motion limited" nature of previous kinetic observations of energy transfer in molecular crystals should not be taken for granted. ${ }^{(17)}$

Finally we discuss the spectral dynamics appearing in the low energy region of Figure 1. As excitons annihilate, ground state molecules reappear. If these molecules return to the ground state in exactly the same vibrational states as they left, the spectral features in Figure 1 should monotonically relax toward zero. This is clearly not happening. We attribute the increase in spectral density at $\mathrm{ca} .13,500 \mathrm{~cm}^{-1}$ with increasing delay time to the reappearance of vibrationally hot ground state molecules.

With the aid of Figure 5, we argue that annihilation events produce electronic ground state molecules with athermal distributions of vibrational energy. Early delay time difference spectra (1 ps) taken at three different ambient temperatures (Figure 5, top) reveal spectral broadening with increasing temperature. This is most evident in the region of bleaching between 13,000 and $14,000 \mathrm{~cm}^{-1}$.

Molecules leaving the ground state at $4 \mathrm{~K}$ and returning at $300 \mathrm{~K}$ would result in the spectrum modeled in the bottom of Figure 5. By subtracting a percentage of the $300 \mathrm{~K}$ spectrum from the 
$4 \mathrm{~K}$ spectrum, the dashed curve in the bottom of Fig. 5 is derived. The weighting factor is determined by the observed degree of recovery of the ground state (monitored at $20,000 \mathrm{~cm}^{-1}$ ). While qualitatively delivering spectral density in the region of $13,500 \mathrm{~cm}^{-1}$, this construct is insufficient to quantitatively explain the observed results.

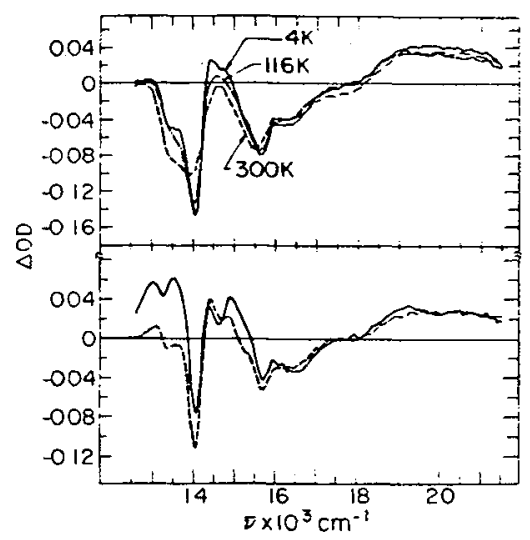

Figure 5

Furthermore, a 300 degree increase in lattice temperature is unreasonable. We calculate a maximal 80 degree temperature rise upon final thermalization of all excitation photons. Rather, we suggest a vibrationally selective conversion of electronic energy into vibrational bottlenecks as a plausible explanation for these results.

Although there are certainly other explanations for this spectral evolution, we expect that transition probabilities describing exciton annihilation must contain vibrational overlap integrals. Franck-Condon considerations should therefore be in evidence. Recent observations of nanosecond $T_{1}$ times in molecular crystals add further plausibility for this argument. ${ }^{(18)}$ One might easily envision far-IR solid state dye lasers pumped by visible light based on these phenomena.

\section{Acknowledgments}

The authors wish to thank V. M. Kenkre, J. L. Skinner and M. D. Sturge for provocative discussions regarding energy transfer in solids, and M. L. Kaplan, I. Mukerji, A. L. Wayda and $\mathrm{R}$. Wolfe for assistance with sample preparation and characterization.

\section{References}

1. A. Bergman, M. Levine and J. Jortner, Phys. Rev. Lett. 18, 593 (1967).

2. N. A. Tolstoi and A. P. Abramov, Sov. Phys. Sol. State 9, 255 (1967).

3. S. D. Babenko, V. A. Benderskii, V. I. Goldanskii, A. G. Lavrushko and V. P. Tychinskii, Phys. Stat. Sol. (b) 45, 91 (1971).

4. R. C. Powell and Z. G. Soos, J. Luminescence 11, 1 (1975).

5. A. J. Campillo, R. C. Yer and S. L. Shapiro, Chem. Phys. Lett. 48, 495 (1977).

6. F. Heisel, J. A. Miehe, B. Sipp and M. Schott, Chem. Phys. Lett. 56, 178 (1978).

7. H. Auweter, A. Braun, U. Mayer and D. Schmid, Z. Naturforsch. 34a, 761 (1979). 
8. D. Schmid, in "Organic Molecular Aggregates, Springer Series in Solid-State Sciences 49," P. Reineker, H. Haken and H. C. Wolf, eds., (Springer-Verlag, Berlin, 1983), p. 184.

9. A. N. Sidorov and I. P. Kotlyar, Opt. Spectroscopy 11, 92 (1961).

10. E. A. Lucia and F. D. Verderame, J. Chem. Phys. 48, 2674 (1968).

11. J. H. Sharp and M. Lardon, J. Phys. Chem. 72, 3230 (1968).

12. C. H. Griffiths and M. S. Walker, Rev. Sci. Instruments 41, 1313 (1970).

13. R. L. Fork, B. I. Greene and C. V. Shank, Appl. Phys. Lett. 38, 671 (1981).

14. E. P. Ippen and C. V. Shank, in "Picosecond Phenomena," C. V. Shank, E. P. Ippen and S. L. Shapiro, Eds., (Springer-Verlag, Berling, 1978), p. 103.

15. F. H. Moser and A. L. Thomas, "Phthalocyanine Compounds" (Reinhold, New York, 1963), p. 15.

16. A. Suna, Phys. Rev. B1, 1716 (1970).

17. V. M. Kenkre and D. Schmid, Chem. Phys. Lett. 94, 603 (1982).

18. T. J. Trout, S. Velsko, R. Bozio, P. L. Decola and R. M. Hochstrasser, J. Chem. Phys. 81, 4746 (1984). 